Article

\title{
Preliminary Investigation into Measurement While Drilling as a Means to Characterize the Coalmine Roof
}

\author{
Manoj Khanal ${ }^{1, *}$, Johnny Qin ${ }^{1}$, Baotang Shen ${ }^{1}$ and Bongani Dlamini ${ }^{2}$ \\ 1 CSIRO Mineral Resources, Brisbane 4069, Australia; Johnny.Qin@csiro.au (J.Q.); Baotang.Shen@csiro.au (B.S.) \\ 2 Cartledge Mining and Geotechnics, Brisbane 4006, Australia; bongani.dlamini@cmandg.com.au \\ * Correspondence: Manoj.Khanal@csiro.au; Tel.: +61-7-33274199
}

Received: 5 December 2019; Accepted: 20 January 2020; Published: 21 January 2020

\begin{abstract}
The variable nature of the coalmine roof poses a challenge to roadway stability during underground coal mining. There have been fatalities and financial losses in the coal mining industry due to roadway failures and roof falls. Generally, the geotechnical and geological data gathered from exploration boreholes, which are drilled at considerable distances from each other, are used to characterize the thickness and quality (including strength) of the coalmine roof. This process provides a limited number of samples that cannot represent the discontinuous nature of the strata in the coalmine roof nor can they form reliable inputs to a digital model of the rock mass component of the digital mine. Gaining confidence in the strata properties of the coalmine roof is necessary for the modelling, design, and maintenance of roadways. The paper describes the progress of the ongoing work to investigate the monitoring while drilling (MWD) concept for characterizing coalmine roofs. Large-scale drilling experiments in synthesized sandwiched rock samples without interfaces were carried out. The drilling response data were analyzed to identify whether the drill data differentiates the various strengths associated with the rock samples. The initial results show that the drilling data can differentiate the synthesized rock samples.
\end{abstract}

Keywords: measurement while drilling (MWD); coalmine; roof strata; drill; digital mine

\section{Introduction}

A major cause of roof instability in underground coalmines is the uncertain variation (for example, thickness, competence, discontinuities) of the coalmine roof. Normally, the geotechnical and geological data gathered from exploration boreholes, which are drilled at considerable distances from each other, are used to characterize the thickness and quality (including strength) of the coalmine roof. This limited data cannot capture the local variability presented in the coalmine roof. Roof support designs must accommodate a certain amount of variability and uncertainty, meaning that some areas are over-supported. Operationally, greater levels of variability and uncertainty are dealt with by means of trigger action response plans (TARPs). If it was possible to reduce the uncertainty by measuring and analyzing various drilling parameters for roof bolting to interpret and gain confidence in the coalmine roof during roadway development, then it would be possible to optimize roof support designs and improve TARP responses. Moreover, this information would be valuable in generating a reliable digital model of the rock mass surrounding the mining process, an important component of a 'digital twin' of a mining operation. From the available literature, it was found that Australian underground coalmines appear to lack a fully integrated measurement while drilling (MWD) system for roadway development [1], so applied research into the topic is required.

This paper discusses MWD as a means to characterize a coalmine roof as part of an integrated and intelligent roadway monitoring and assessment system that is being developed at the Coal Mining Research Program in the Commonwealth Scientific and Industrial Research Organization (CSIRO) as 
an aid to mining operations and as an input into development of the digital mine. Figure 1 shows a broader concept of the key components of this system and its applications.

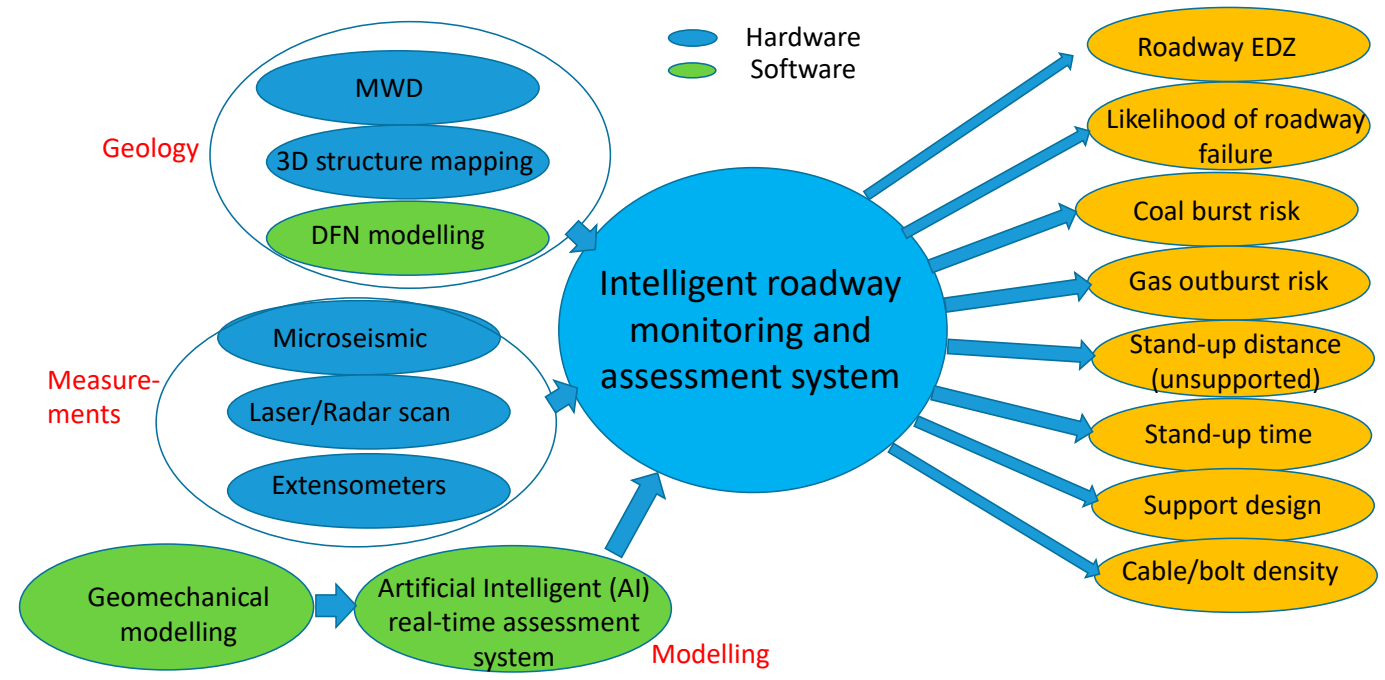

Figure 1. Key components the intelligent roadway monitoring and assessment system and its applications.

For underground mining operations, including longwall mining, bord and pillar mining, and block caving in metalliferous mines, roadway development is a critical part. Roadways are used to transport mining personnel, equipment, mined coal, and minerals to the ground surface. The roadway system is a lifeline in any underground mining operation to support and provide critical functions in day-to-day activities and therefore they need to be stable, reliable, and functional. In addition to the high cost of development, there is a huge ongoing cost in the maintenance of these roadways. A one-day stoppage of underground longwall coal extraction would cost more than a million dollars, including production loss and recovery costs, to a mine.

Further pressure is being placed on roadway development due to mines facing deeper and more challenging geological operating conditions. As a solution to these problems, remote operation methods are being implemented. For these systems, reliable roof characterization methods are required for remote monitoring and digital geological model generation.

The challenges facing effective roadway design include unfavorable geotechnical conditions, lack of real-time strata monitoring, inadequate understanding of the dynamics and types of failure mechanisms, and insufficient geological data. A real-time predictive tool that can provide information on what is ahead on the drilling process while developing the roadways in underground coalmines would provide valuable data that is not currently available. The integration of the MWD concept, as shown in Figure 2, provides a high-value input into an intelligent digital mining system. The real-time geological data obtained from the drill sensors are collated and analyzed with a suitable algorithm, which is already fed into the MWD analysis box (shown in Figure 2) to characterize the strength and nature (layered or massive) of the roof strata. After the characterization of the roof strata, the roof bolting algorithm (which is a part of the intelligent digital mine but not covered in this paper) performs the calculation and optimization of the roof bolts required for adequate roof support and is passed on to the roof bolter. This whole process will be a part of the intelligent digital mining concept shown in Figure 2. 


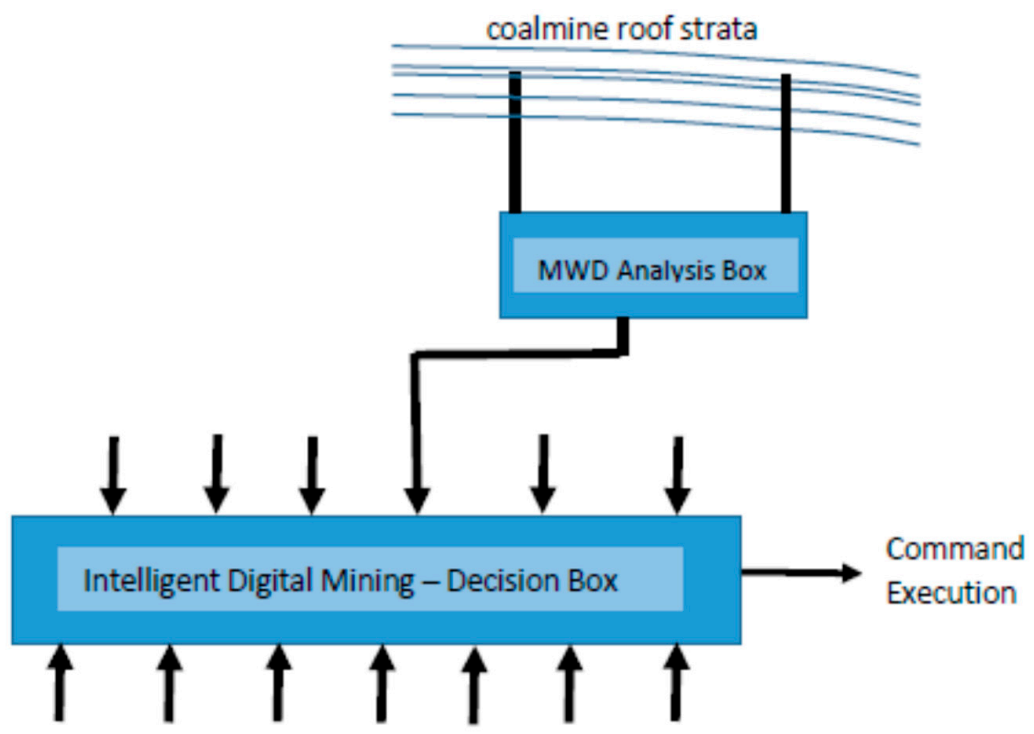

Figure 2. Role of MWD in intelligent mining.

\section{MWD History}

The method was first developed for the petroleum exploration industry [2]. The literature has examples of laboratory experiments, field trials, and the development of instruments to monitor while drilling [2-12]. Reference [6] provided a brief review of recent improvements on instrumented drills used in ground characterization and highlighted issues that are still lagging in using these instruments. Four instruments for roof bolt drills that can acquire roof data during roof drilling are discussed [6]. These tools have been developed by (a) Parvus Corporationn (Salt Lake City, UT, USA) (b) Muroran Institute of Technology (Hokkaido, Japan), (c) Robotics Institute of Carnegie Mellon University (Pittsburgh, PA, USA), and (d) JH Fletcher \& Company (Huntington, WV, USA).

Apart from the JH Fletcher \& Company system, as per our understanding, none of the available literature demonstrates the use of these tools in either commercial, prototype, or development status in Australia. Data obtained from one of the examples of MWD in a concrete block reproduced in Figure 3 (taken from [8] with acknowledgement).

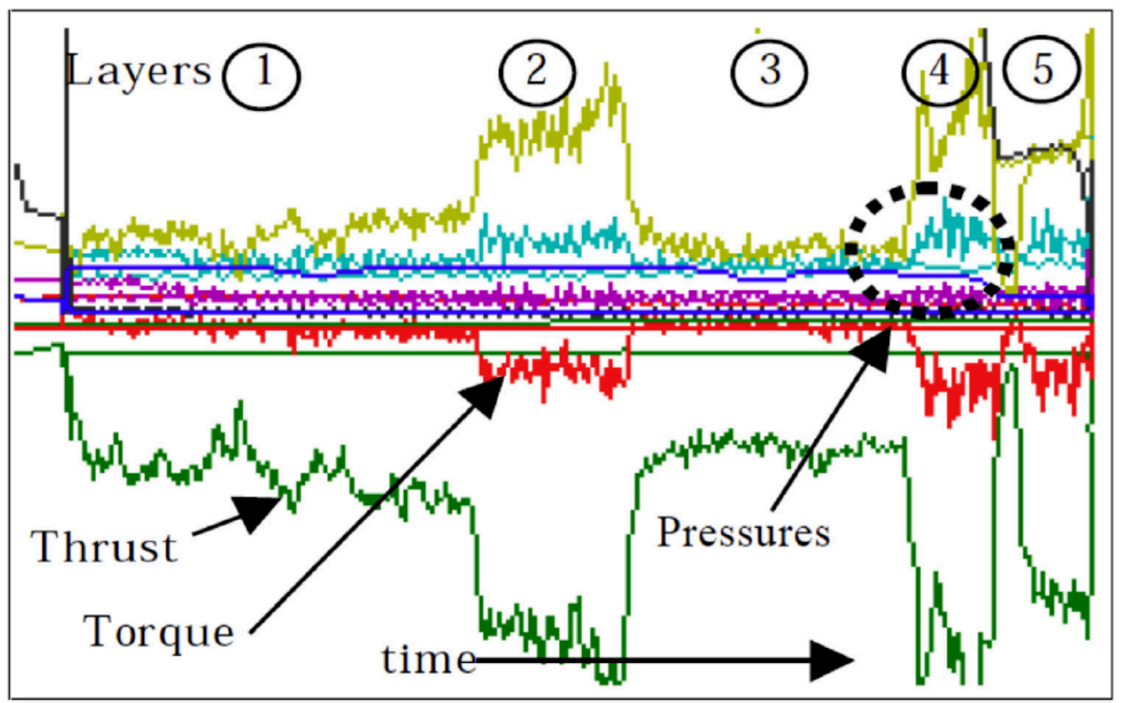

Figure 3. Data acquired during concrete block drilling for MWD (with acknowledgement to [8]). 
Figure 3 illustrates the distinctive combinations of drilling parameters when different strata are encountered. Generally, the specific energy of drilling (mechanical work done by drill bit per unit volume of excavated material) [11] and, recently, the rotation to thrust power ratio [7] are used to measure the energy required to fracture rocks and classify rock types. Researchers have investigated the use of the specific energy of drilling as an indicator of the uniaxial compressive strength of the samples [5].

\section{Methods and Materials}

Some of the issues that are challenging in the development of MWD for the coal mining environment in this project while doing experiments and field study include the accuracy in analyzing and interpreting the measurement data, accurately classifying coal and other like materials (for example, shale), accuracy in deriving rock properties [2,7], and identifying smaller joints [13].

Most of the literature shows the development of the MWD concept on either the laboratory scale with the synthesized samples $[5,13,14]$ or drill data collected from the mine [7] with their own analysis and explanation of the acquired signals and are in the research stage. However, these results are encouraging (for example, $[5,14])$.

The objectives of this research were (a) to investigate the applicability of the MWD concept to perform geotechnical characterization of coalmine roofs to inform geological and geotechnical digital models, and (b) to detect "signatures" of changes in roof strata to assist in real-time operational decision making.

The concept of MWD, while sampling as close to the roadway face as possible, has the potential to allow for early detection and response to geotechnical hazards (for example, thinning roof coal layer, weak lithology, seam splits, discontinuities, voids). With the installation of sensors on the drills, the parameters (for example, toque, penetration rate), which are monitored and gathered during the drilling process, will be analyzed to extract valuable information on roof characteristics that will help in developing a predictive methodology for improved coalmine roof characterization.

In theory, various methods, including analytical, numerical, and experimental, can be used to analyze the applicability of MWD to the characterization of coalmine roofs [2-8,11,15-17]. Analytical and numerical methods provide a straightforward means to understand the immediate effect of various geotechnical parameters on drilling and bolting operations. However, the main concept these methods lack is the incorporation of heterogeneity and complexity in the geology (for example, inter-penetration of layers, voids, pinching of various layers) of the strata properties in the analysis. A limited solution could be achieved by performing several sensitivity analyses, but a sensitivity analysis does not provide any useful real-time information regarding a combination of heterogeneity and complexity so is not meaningful for operational purposes. Consequently, there is a place for experimental observations and analysis on synthesized and real samples to provide significant information on what type of strata lies ahead while drilling.

Normally, experienced drill operators can provide a qualitative comparison of strata behaviors during drilling based on various drill parameters, for example, the feed rate, vibration, sound etc. The aim of this research is to capture these cues through MWD via various signals, and process and interpret these signals to develop a predictive tool to characterize the strata.

The research was planned in multiple stages as (a) performing experiments on various synthesized laboratory samples, (b) developing an analysis method with the data acquired from the synthesized laboratory samples, (c) testing the real rock samples with the developed analysis method, and (d) conducting field trials on real-time data. Currently, this project is in its initial stage.

Therefore, this paper presents the progress of the ongoing work of the initial stage. In this initial stage, various synthesized sandwiched rock samples with synthesized interfaces (as shown Figure 1) were drilled in the laboratory. The drilling machine had sensors attached and the laboratory testing was performed in a controlled environment. The data obtained were analyzed to see if any significant differences exist between various strength layers in order to investigate the applicability of MWD 
in synthesized and real rock samples. Finally, and ideally, the aim was to provide a tool box, which takes the real-time geological information from the MWD sensors, process it with specific algorithms to optimize roadway supports, and update the mine's digital geological model, support plans, and designs, if needed. Some initial experiments have already been conducted and the results to date are discussed in this paper. Since the research is at an early stage, ongoing experiments will confirm or suggest a new approach to analyze the observations noted in this paper.

\section{Experimental Program}

\subsection{Drill Rig}

CSIRO's Rock Cutting Laboratory field-scale drill rig shown in Figure 4 was used for this project. The specification of the drill rig is given in Table 1. Various instruments to measure spindle revolution per minute (rotary speed), torque at the spindle, spindle motor input hydraulic pressure, pulldown force, and mast displacement (position) are installed in the rig to facilitate drilling data acquisition.

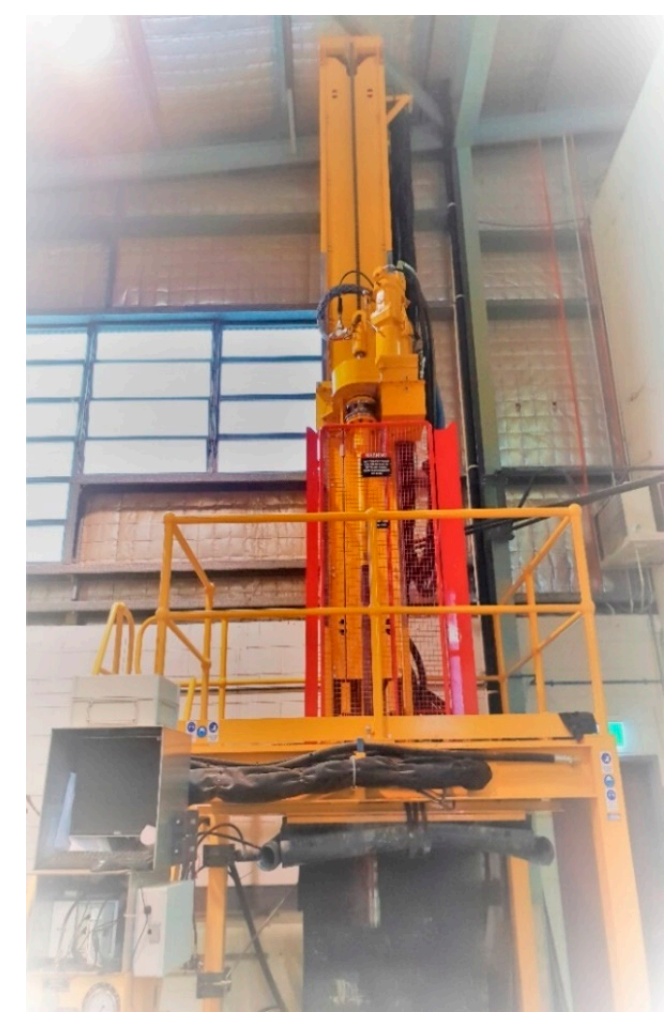

(a)

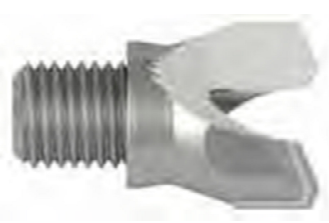

(b)

Figure 4. (a) Drill rig used in the experiment. (b) Sample drill bit.

Table 1. Specification of drill rig.

\begin{tabular}{cc}
\hline Spindle Speed & 0-1250 RPM, 2 Speed Gearbox \\
\hline Max Torque & $4150 \mathrm{Nm}$ \\
Max Weight on Bit & $60 \mathrm{kN}$ \\
Vertical Feed Rate & $0-3 \mathrm{~m} / \mathrm{s}$ \\
Mast Stroke & $2.3 \mathrm{~m}$ \\
Max Water Flow & $\sim 50 \mathrm{~L} / \mathrm{min}$ at mains pressure \\
Air Compressor & 600 CFM at $190 \mathrm{psi}$ \\
DTH Hammer & Drillroc 5 inch \\
Dust Suppression with DTH Hammer & 1450 psi water at $8 \mathrm{~L} / \mathrm{min}$ at top swivel \\
\hline
\end{tabular}


Sensors to measure drilling parameters, such as the penetration rate, torque, rotary speed, vibration etc., are becoming common add-ons in drilling machines. The monitoring of these parameters can offer valuable information regarding the geomechanical properties of strata at the drill bit during drilling. For example, the pull-down force can indicate the strength and hardness of the rock. As expected, the pull-down force decreases in soft rock transitions and increases in harder-stronger transitions [18]. The intensity of vibration identifies different strengths between strata types. Torque measures the variation between soft and hard rocks.

Drill rods, drill adaptors, and drill bits of dimensions of 38 and $28 \mathrm{~mm}$ with M16 thread were sourced from third party suppliers. A drill bit example is also shown in Figure 4. As per the suppliers' data, the drill bit should easily drill through materials up to 50 to $60 \mathrm{MPa}$ uniaxial compressive strength.

\subsection{Synthesized Sample Preperation}

Synthesized layered rock samples of varying strength and thickness were prepared. These samples were prepared to resemble the variable (strength and thickness) nature of a typical coalmine roof. Key drilling parameters, such as the torque, rotary speed, hydraulic pressure, and force, were captured while drilling through the different samples.

A fundamental approach was adopted to prepare synthetic rock samples and conduct drilling experiments. A general purpose Portland cement that complies with the AS3972 standard and general purpose construction sand were chosen for the experiments. Double-washed and kiln-dried sand, with a 0.2- to 0.6-mm sieve size particles was used to prepare the mortar samples.

First, three classes of mortar representing low, medium, and high strength geo-materials were prepared with the cement and sand mixture as shown in Table 2. Each sample was $0.4 \mathrm{~m}^{2}$ in area with a height of $0.3 \mathrm{~m}$ and a volume of $0.048 \mathrm{~m}^{3}$. These samples are expected to represent various strengths of the strata that are encountered in the coalmine roof. It should be noted that the strength values shown are estimates only and uniaxial compressive tests should be conducted to confirm these values. Figure 5 shows the sample preparation process at the laboratory.

Table 2. Used ratio and tested uniaxial compressive strength of each sample.

\begin{tabular}{|c|c|c|c|c|c|}
\hline$\#$ & Type & Piece & Dimension, $\mathbf{m}$ & Estimated UCS *, MPa & Mixing Ratio (Sand:Cement) \\
\hline 1 & Weak & 4 & $0.4 \times 0.4 \times 0.3$ & 10 & $4: 1$ \\
\hline 2 & Moderate & 4 & $0.4 \times 0.4 \times 0.3$ & 22 & $2: 2$ \\
\hline 3 & Strong & 4 & $0.4 \times 0.4 \times 0.3$ & 40 & $1: 4$ \\
\hline
\end{tabular}

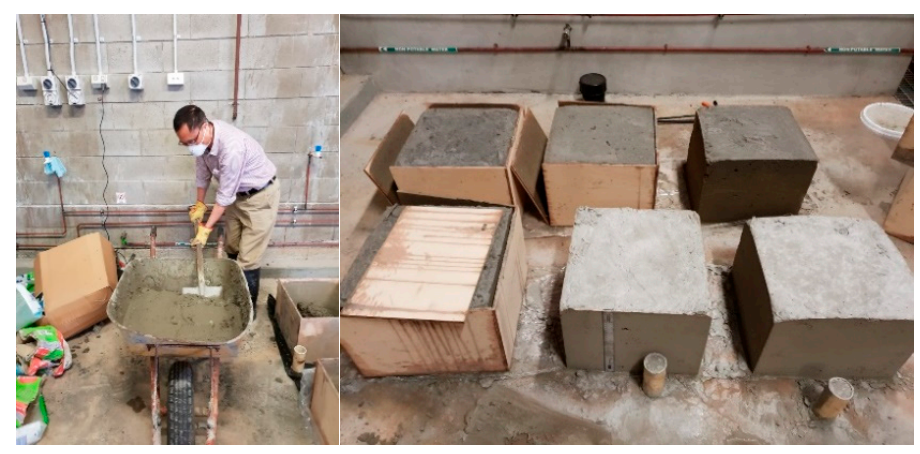

Figure 5. Examples of sample preparation and samples.

The individual samples were left and regularly watered for 35 days for curing. These samples were then assembled in a 3 by 4 matrix-type setup, shown in Figure 6, in order to form a representative geomechanical setup comprising conceptual lithological units of various strengths. These samples were cased in a large concrete structure of a dimension of $1.2 \mathrm{~m}$ square with a $0.9-\mathrm{m}$ height as shown in 
the right-hand picture of Figure 6. This outer casing is needed to contain the samples firmly during the drilling process. Figure 7 shows the experimental setup.
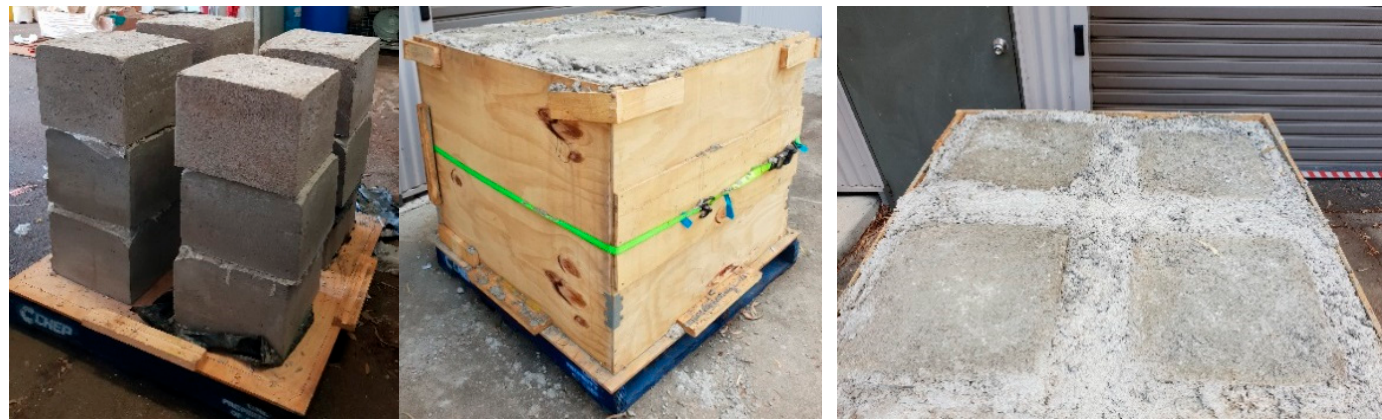

Figure 6. Test design consisting of various lithological units embedded in concrete.
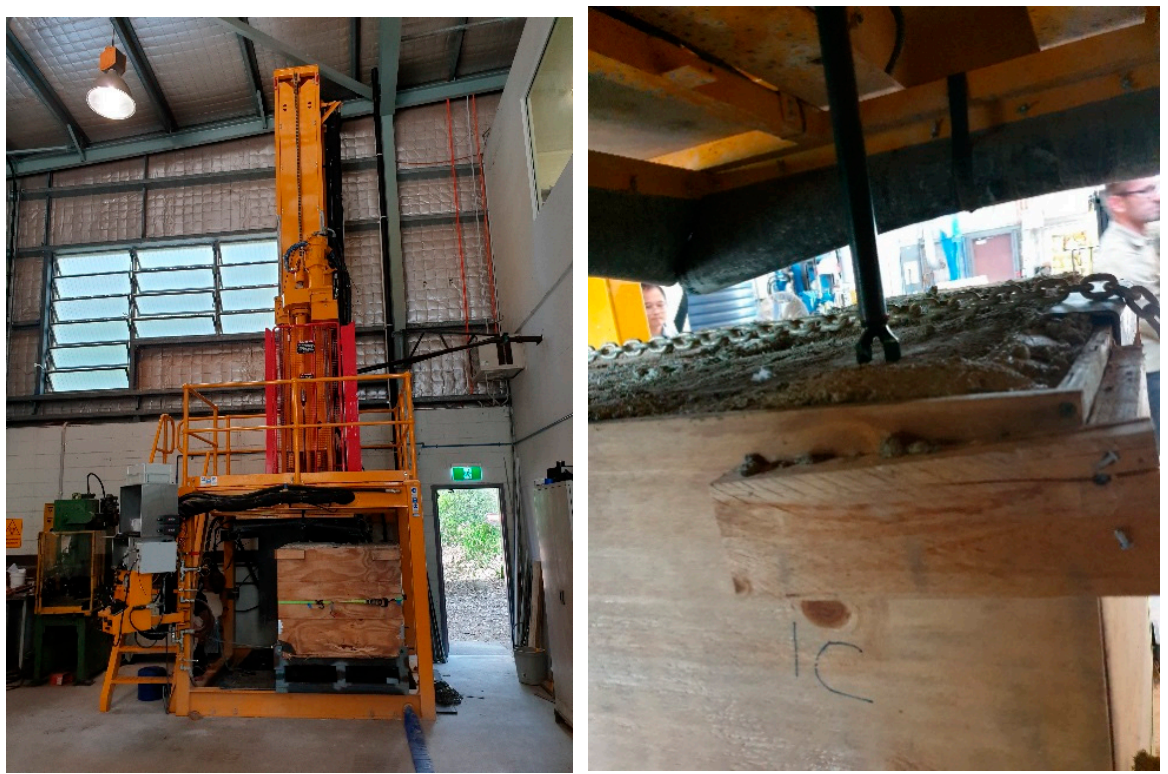

Figure 7. Experimental set up.

\section{Results and Discussion}

In each column, three rows of synthesized samples were placed. The top row samples were weakest, the middle row samples were moderate, and the bottom row samples were the strongest, as described in Table 2. Several drilling experiments were carried out.

In this preliminary study, 10 holes were drilled in one column. The raw data obtained from the drill rig data acquisition system were calibrated as per the machine and sensor calibration factors. The raw data were cleaned to remove the spurious data. Then, using a suitable data processing script in the python programming language, the data were analyzed and plotted. Preliminary results while drilling a column of the blocks are shown in Figure 8. This example data is from the same drill hole. These results are promising as the various curves shown in the figure show a distinct response of the various sample blocks for the assigned drilling revolution per minute. In the displacement figure, due to the void interface, there are some kinks at around 480 and $970 \mathrm{~s}$. Depending on the material the drill bit is passing through, the reaction on the weight on the bit is changing. The weaker block on the top of the drilled column does not provide much resistance to the drill bit, whereas the second block, which is stronger than the first block, provides some resistance to the drill bit. The third block is strongest of all, therefore it provided much resistance to the drill bit while drilling. A similar observation can be noted for the torque on the bit. 

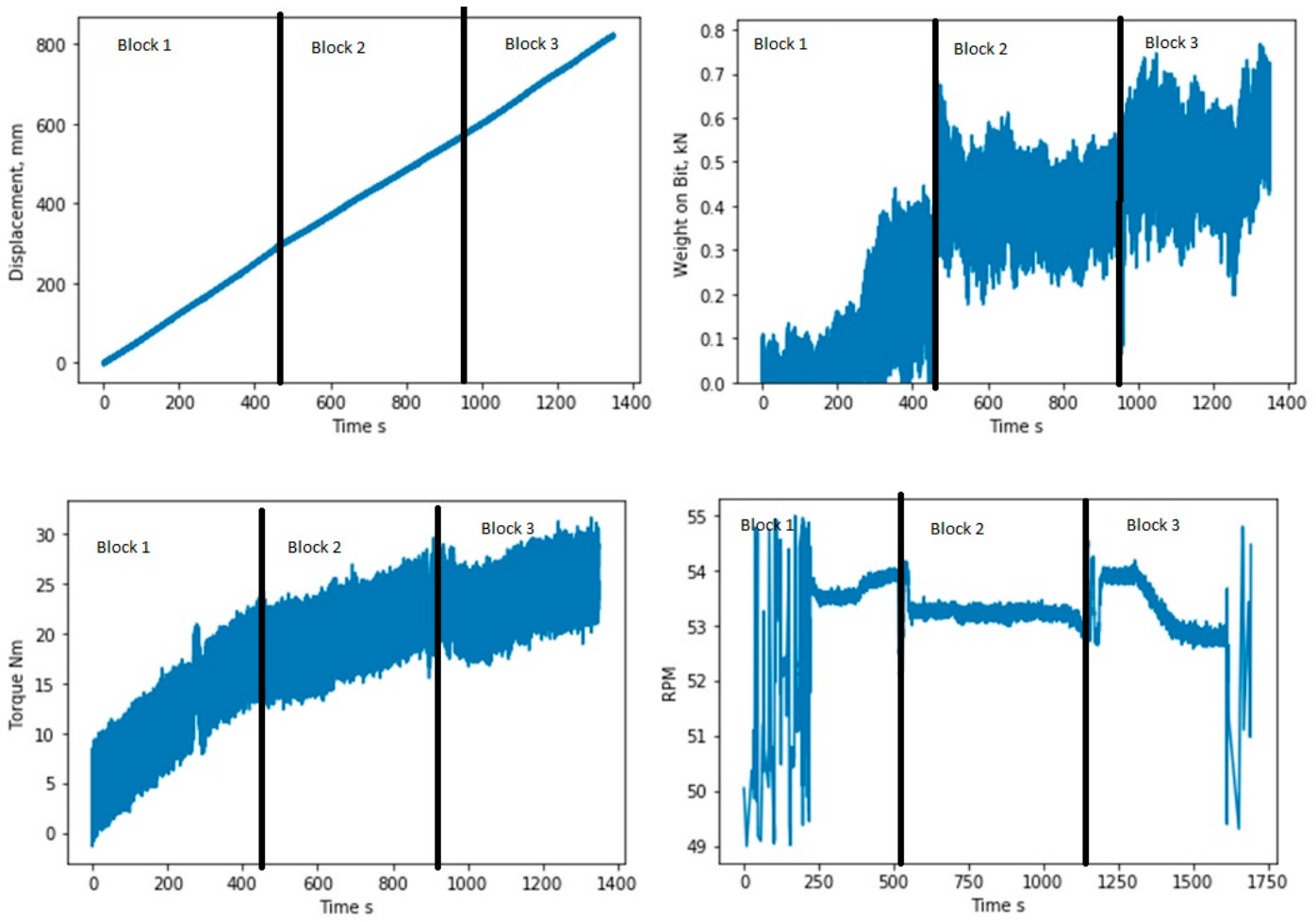

Figure 8. Preliminary results obtained while drilling a column of blocks (displacement, mm; weight on bit, kN; torque, Nm, and time, s). Parameters: $50 \mathrm{rpm}$, weight on bit $1.5 \mathrm{kN}$, and drill bit diameter $28 \mathrm{~mm}$.

With many tests, we expect to observe similar differentiation of the magnitudes for the torque and response on other input parameters while the drilling rod passes through blocks of various strengths. It should be noted here that this is just the beginning of the research in this area. The results presented and discussed here will need to be repeated under a range of operating conditions to test the hypothesis discussed in this paper. In the next set of experiments, the plan is to conduct at least 200 experiments with a range of drilling parameters, both with and without a synthesized interface between the blocks in the columns. It is planned that combinations of different layers with varying strengths will be used. Thus, our hypothesis will be tested in a number of real underground coalmine roof development scenarios. The obtained data will be analyzed with a suite of machine learning algorithms, with the goal of achieving a functional result.

The risk to achieving the expected outcomes and benefits of the project will depend on the ability to identify and interpret the signatures obtained from the experiments on synthesized samples and on real rock samples. In addition to the accuracy in analyzing, interpreting and measurement issues, accurately classifying coal and shale in field experiments, and accuracy and reliability in deriving rock properties with the drilling data could be considered as challenges and risks in developing and using MWD in the coal mining environment [2,7]. Previous work in this area suggests good prospects that these challenges are surmountable and that a practical MWD system can be developed.

\section{Conclusions}

Preliminary experiments were conducted to identify the applicability of measurement during the drilling concept in coal mining scenarios, where there are a lot of alike geo-materials present in the strata. The very first experiments have shown to be promising; however, it is still too early to comment any further on the applicability of the concept in underground coal mining, particularly in roadway development. 
At this preliminary stage, the results obtained from the MWD are promising as they show distinct responses of the various sample blocks in a controlled environment. The weight on the bit varies with the strength of the blocks. The torque on the bit also shows a dependency on the strength of the blocks.

The successful analysis, development, and implementation of the MWD analysis box with suitable hardware can improve the efficiency and production of underground coal mining. The most important improvement would be a reduction of human exposure to the hazardous underground coal mining environment and a step towards improved automation and remote management, which can eventually lead to the achievement of the integrated intelligent digital mine concept. The real-time data obtained from the MWD could also be used in modelling, calibration, and validation of the physical, numerical, and analytical model. Further application of the MWD would be in the hazardous environment experienced in other fields, for example, civil engineering.

Author Contributions: Conceptualization, Methodology, Analysis and Investigation by M.K., J.Q. and B.S.; Resources by M.K., J.Q., B.S. and B.D.; original draft preparation, writing, review and editing by M.K., B.S., J.Q. and B.D. All authors have read and agreed to the published version of the manuscript.

Funding: This research was funded by the Strategic Challenge Project, CSIRO.

Acknowledgments: The authors would like to acknowledge Hua Guo for his support on this project, and Xing Li for providing the laboratory facility, Craig Harbers and Danial Williams in conducting the experiments. The authors would also like to thank Paul Buddery for this constructive suggestion on the research work. The authors would also like to acknowledge David Hainsworth for his valuable feedback on the paper and Andy Wilkins for constructive discussions.

Conflicts of Interest: The authors declare no conflict of interest.

\section{References}

1. Buddary, P.; Mining Geotechnical Engineer, Brisbane, Australia. Personal communication, 2019.

2. Li, Z.; Itakura, K.-I.; Ma, Y. Survey of measurement-while-drilling technology for small-diameter drilling machines. Electron. J. Geotech. Eng. 2014, 19, 10267-10282.

3. Bahrampour, S.; Rostami, J.; Ray, A.; Naeimipour, A.; Collins, C. Ground characterization and roof mapping: Online sensor signal-based change detection. Int. J. Min. Sci. Technol. 2015, 25, 905-913. [CrossRef]

4. Basarir, H.; Wesseloo, J.; Karrech, A.; Pasternak, E.; Dyskin, A. The use of soft computing methods for the prediction of rock properties based on measurement while drilling data. In Proceedings of the Eighth International Conference on Deep and High Stress Mining, Australian Centre for Geomechanics, Perth, Australia, 28-30 March 2017.

5. Finfinger, G.L.; Peng, S.; Gu, Q.; Wilson, G.; Thomas, B. Mining Publication: An Approach to Identifying Geological Properties from Roof Bolter Drilling Parameters. In Proceedings of the 19th International Conference on Ground Control in Mining, West Virginia University, Morgantown, WV, USA, 8-10 August 2000.

6. Kahraman, S.; Rostami, J.; Naeimipour, A. Review of Ground Characterization by Using Instrumented Drills for Underground Mining and Construction. Rock Mech. Rock Eng. 2016, 49, 585-602. [CrossRef]

7. Leung, R.; Scheding, S. Automated coal seam detection using a modulated specific energy measure in a monitor-while-drilling context. Int. J. Rock Mech. Min. Sci. 2015, 75, 196-209. [CrossRef]

8. Rostami, J.; Kahraman, S.; Naeimipour, A.; Collins, C. Rock characterization while drilling and application of roof bolter drilling data for evaluation of ground conditions. J. Rock Mech. Geotech. Eng. 2015, 7, 273-281. [CrossRef]

9. Segui, J.B. MWD Exposes Rock Properties but also the Industry Resistance to Change; LinkedIn: Mountain View, CA, USA, 2019.

10. Segui, J.B.; Higgins, M. Blast Design Using Measurement While Drilling Parameters. Fragblast 2002, 6, 287-299. [CrossRef]

11. Teale, R. The concept of specific energy in rock drilling. Int. J. Rock Mech. Min. Sci. Geomech. Abstr. 1965, 2, 57-73. [CrossRef] 
12. Utt, W.K.; Miller, G.G.; Howie, W.L.; Woodward, C.C. Drill Monitor with Strata Strength Classification in Near-Real Time; Report of investigations (National Institute of Occupational Safety and Health); Walter, K., Utt, W.K., Spokane, L., Eds.; U.S. Dept. of Health and Human Services Public Health Service Spokane Research Laboratory: Washington, DC, USA; Centers for Disease Control and Prevention: Atlanta, GA, USA; National Institute for Occupational Safety and Health: Cincinnati, OH, USA, 2002; p. 9658.

13. Liu, W.; Saab, S.S., Jr.; Rostami, J.; Ray, A. Improving the capability of detecting joints and fractures in rock mass from roof bolt drilling data by using wavelet analysis. Int. J. Oil Gas Coal Technol. 2019, 20, 97-112. [CrossRef]

14. Itakura, K.; Tomita, S.; Iguchi, S.; Ichihara, Y.; Mastalir, P.; Bergner, T.; Coyte, C. Roof Geostructure Logging System Using Portable Pneumatic Drilling Machine. In Proceedings of the Rock Mechanics in Underground Construction: ISRM International Symposium 2006: 4th Asian Rock Mechanics Symposium, Singapore, 8-10 November 2006.

15. Kadkhodaie-Ilkhchi, A.; Monteiro, S.T.; Ramos, F.; Hatherly, P. Rock Recognition from MWD Data: A Comparative Study of Boosting, Neural Networks, and Fuzzy Logic. IEEE Geosci. Remote Sens. Lett. 2010, 7, 680-684. [CrossRef]

16. King, R.L.; Hicks, M.A.; Signer, S.P. Using unsupervised learning for feature detection in a coal mine roof. Eng. Appl. Artif. Intell. 1993, 6, 565-573. [CrossRef]

17. Vezhapparambu, V.S.; Eidsvik, J.; Ellefmo, S.L. Rock Classification Using Multivariate Analysis of Measurement While Drilling Data: Towards a Better Sampling Strategy. Minerals 2018, 8, 384. [CrossRef]

18. Scoble, M.; Peck, J.; Hendricks, C. Correlation beween rotary drill performance parameters and borehole geophysical logging. Min. Sci. Technol. 1989, 8, 301-312. [CrossRef]

(C) 2020 by the authors. Licensee MDPI, Basel, Switzerland. This article is an open access article distributed under the terms and conditions of the Creative Commons Attribution (CC BY) license (http://creativecommons.org/licenses/by/4.0/). 